\title{
PERANCANGAN SISTEM INFORMASI PERSEDIAAN DAN PENJUALAN PADA TOKO RIA BANGUNAN DENGAN MENGGUNAKAN BAHASA PEMROGRAMAN VISUAL BASIC 2010 DAN DATABASE MYSQL
}

\author{
Novri Ultariani ${ }^{1}$, Nursaka Putra ${ }^{2}$, Amroni $^{3}$ \\ Universitas Putra Indonesia "YPTK", Padang ${ }^{1}$, Universitas Catur Insan Cendekia ${ }^{2,3}$ \\ Jl. Kesambi 202, Kota Cirebon, Jawa Barat. Telp (0231)220350 \\ e-mail: novriultariani50@ gmail.com ${ }^{1}$, nursaka.putra@cic.ac.id ${ }^{2}$, amroni@ cic.ac.id ${ }^{3}$
}

\begin{abstract}
Abstrak
Berdasarkan penelitian yang telah dilakukan pada toko Ria Bangunan di Dhamasraya ternyata sistem pengolahan data barang dan transaksi penjualan masih dilakukan secara manual sehingga sering terjadi kesalahan. Dengan adanya perancangan sistem informasi pengendalian barang menggunakan metode Economic Order Quantity dan Reorder Point dibantu dengan bahasa pemrograman VB-NET, akan memberikan solusi yang lebih baik terhadap masalah-masalah yang dihadapi. Hasil dari metode ini akan meningkatkan sistem dan meminimalisir kesalahan dalam pengolahan data barang serta transaksi penjualan. Mempercepat dan mempermudah bagian administrasi dalam membuat laporan, sehingga dapat menghasilkan informasi yang akurat.
\end{abstract}

Kata kunci : Penjualan, Persediaan, VB-NET, MySQL

\section{Abstract}

Based on the research that has been done at the Ria Bangunan shop in Dhamasraya, it turns out that the data processing system for goods and sales transactions is still done manually so mistakes often occur. With the design of the goods control information system using the Economic Order Quantity and Reorder Point methods, assisted by the VB-NET programming language, will provide a better solution to the problems faced. The results of this method will improve the system and minimize errors in processing data on goods and sales transactions. Speed up and simplify the administration in making reports, so that it can produce accurate information.

Keywords : sale, supply, VB-NET, MySQL

\section{PENDAHULUAN}

\subsection{Latar Belakang Masalah}

Perkembangan ilmu pengetahuan dan teknologi telah memperlihatkan kemajuan, salah satu contoh kemajuan yang dirasakan terciptanya komputer dan internet. Pemanfaatan komputer dalam kehidupan masyarakat semakin berkembang. Karena komputer bukan hanya sebagai alat pengolah data, namun juga sebagai media penyebaran informasi yang begitu cepat dan efisien dalam segala hal.

Toko Ria adalah sebuah toko yang menjual berbagai macam bahan bangunan, dalam proses jual beli dan pengelolaan datanya masih bersifat manual. Contohnya dalam pengelolaan data pembelian, pengelolaan stock dan pembuatan laporan yang kurang efektif dan membutuhkan waktu yang lama. Akibatnya sering terjadi kesalahan dalam pencatatan nota penjualan, sering terjadi kesalahan dalam

Perancangan Sistem Informasi Persediaan dan Penjualan Pada Toko Ria Bangunan Dengan Menggunakan Bahasa Pemrograman Visual Basic 2010 dan Database MYSQL( Novri Ultariani, Nursaka Putra, Amroni) 
perhitungan persediaan barang dan lambatnya dalam pembuatan laporan sehingga terjadi kendala dalam pengambilan keputusan.

\subsection{Rumusan Masalah} berikut :

Berdasarkan latar belakang masalah diatas, maka penulis mencoba merumuskan masalah sebagai

1. Bagaimana dengan sistem baru yang dirancang dapat memberikan pelayanan terhadap konsumen serta menunjang operasional pemasaran pada toko Ria bangunan?

2. Bagaimana dengan sistem baru yang dirancang ini dapat mengontrol persediaan barang dalam kapasitas yang besar, sehingga tidak terjadi penumpukan ataupun kelangkaan data ?

\subsection{Ruang Lingkup Penelitian}

Agar penulisan penelitian ini tujuannya terarah dan permasalahan yang sedang dihadapi tidak terlalu luas maka penulis menetapkan batasan-batasan terhadap masalah yang akan diteliti, yaitu: pada persediaan produk atau barang. Dalam hal ini penulis memfokuskan pada sistem informasi persediaan yang sedang berjalan di toko Ria bangunan.

\subsection{Tujuan Penelitian}

Adapun tujuan penelitian yang penulis lakukan pada toko Ria bangunan ini adalah :

1. Membantu pihak toko Ria bangunan dalam memberikan pelayanan yang baik kepada konsumen serta mampu mengoperasikan pemasaran produk atau barang guna mencapai pemasaran yang optimal.

2. Menghasilkan laporan-laporan secara terperinci serta memudahkan pihak toko mencari informasi yang dibutuhkan dalam berskala besar.

\section{LANDASAN TEORI}

\subsection{Konsep Dasar Sistem Informasi}

Istilah sistem bukanlah hal yang asing bagi kebanyakan orang. Seringkali, sistem mengacu pada komputer seperti IBM PC atau Macintosh, tetapi juga bisa kearah yang lebih luas seperti sistem tata surya atau bahkan ke hal-hal yang lebih spesifik seperti sistem respirasi mamalia.

Pada dasarnya, sistem adalah sekumpulan elemen yang saling terkait atau terpadu yang dimaksudkan untuk mencapai suatu tujuan. Secara lebih spesifik, tujuan sistem informasi bergantung pada kegiatan yang ditangani (Abdul Kadir, 2014).

\subsubsection{Pengertian Sistem}

Sistem adalah kumpulan atau himpunan dari unsur atau variabel-variabel yang saling terkait, saling berinteraksi, dan saling tergantung satu sama lain untuk mencapai tujuan (Hamim Tohari, 2014).

\subsubsection{Siklus Hidup Pengembangan Sistem (System Development Life Cycle / SDLC)}

Siklus Hidup Pengembangan Sistem atau Sistem Development Life Cycle (SDLC) adalah proses pengembangan atau mengubah suatu sistem perangkat lunak dengan menggunakan mengembangkan sistem-sistem perangkat lunak sebelumnya berdasarkan best practice atau caracara yang sudah teruji baik (Rosa A.S dan M. Shalahuddin, 2014).

\subsubsection{Sistem Informasi Persediaan}

Setiap perusahaan, apakah itu perusahaan perdagangan ataupun perusahaan pabrik (manufacture) serta perusahaan jasa selalu mengadakan persediaan. Tanpa adanya persediaan, para pengusaha akan dihadapkan pada resiko bahwa perusahaannya pada suatu waktu tidak dapat memenuhi keinginan pelanggan yang memerlukan permintaan barang atau jasa (Maulan Irwadi. 2015. Bahan Baku Produksi. Vol. 2. No. 1. ISSN-P : 2407-2184).

\subsubsection{Pengertian Database}

Database adalah suatu aplikasi yang menyimpan sekumpulan data. Setiap database mempunyai API tertentu untuk membuat, mengakses, mengatur, mencari, menyalin data yang ada di dalamnya (Jubille Enterprise, 2015). Database yaitu kumpulan file-file yang berhubungan satu dengan yang 
lainya, diatur sedemikian rupa sehingga dapat digunakan oleh beberapa program aplikasi database (Rini Asmara. 2014. Sistem Informasi Penjadwalan Kuliah : Studi Kasus Institut Agama Islam Negeri (IAIN) Imam Bonjol Padang. Vol. 2. No. 1. ISSN : 2338-2724).

\subsection{Pengertian Sistem Informasi}

Sistem Informasi adalah merupakan gabungan dari empat bagian utama. Keempat bagian utama tersebut mencakup perangkat lunak (software), perangkat keras (hardware), insfrastruktur dan Sumber Daya Manusia (SDM) yang terlatih (I Putu Agus Eka Pratama, 2014).

\section{METODOLOGI PENELITIAN}

Dalam suatu penelitian urutan kegiatan untuk menyelesaikan suatu permasalahan sangatlah penting diterapkan. Agar tujuan tersebut berhasil, penulis melakukan proses dengan menggunakan kerangka penelitian sebagai urutan dalam pengerjaan yang baik, terdapat pada gambar 1 berikut :

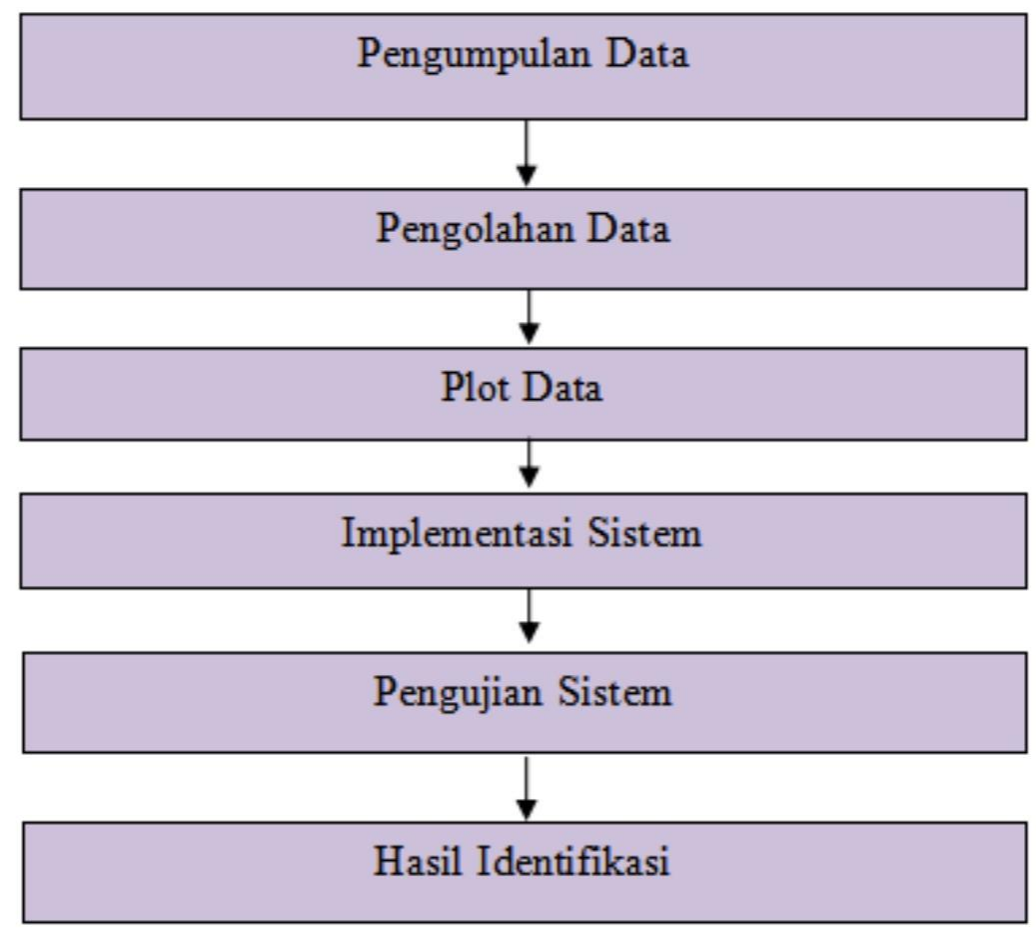

Gambar 1. Kerangka Penelitian

\section{ANALISA DAN PERANCANGAN}

\subsection{Analisa Sistem}

Analisa sistem perlu dilakukan untuk mengetahui dan memahami masalah yang dihadapi oleh sistem informasi pengolahan data pada saat ini. Analisis sistem merupakan dasar dalam merencanakan dan merancang sistem yang baru, dimana sistem yang lama akan dijadikan perbandingan terhadap sistem yang baru yang akan diterapkan. 


\subsubsection{Use Case Diagram}

Adapun interaksi antara pengguna dengan sistem terlihat pada gambar 2 berikut.

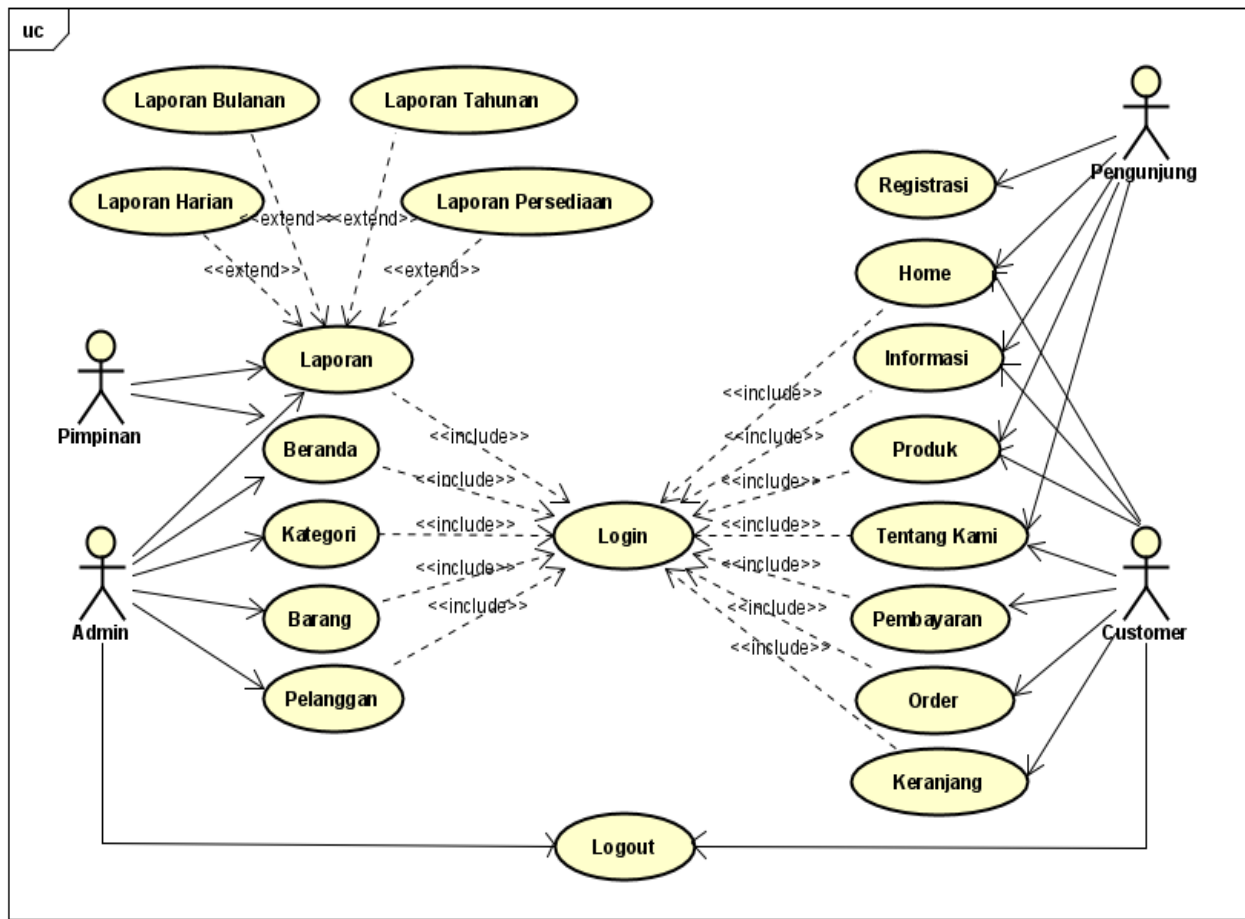

Gambar 2. Use Case Diagram

\subsubsection{Activity Diagram Admin}

Activity Diagram pada Administrator bisa dilihat pada gambar 3 berikut ini.

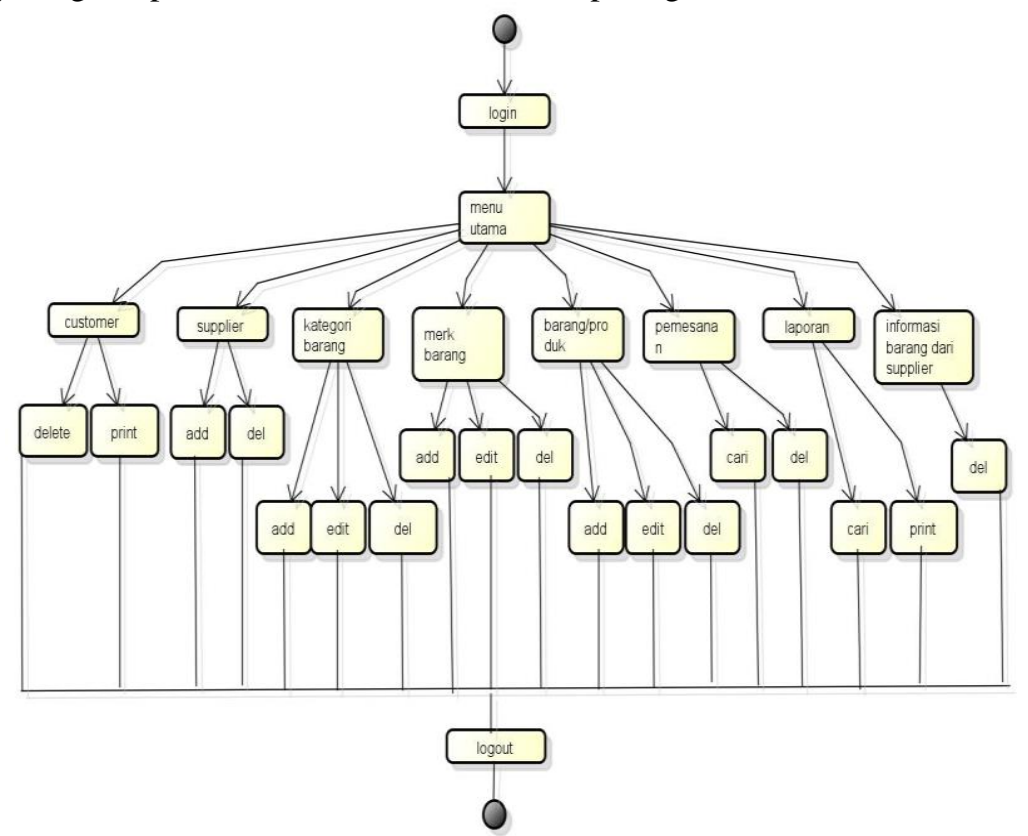

Gambar 3. Activity Diagram Admin 


\subsubsection{Sequence Diagram Login Admin}

Pada bagian ini menjelaskan bagaimana login admin kedalam sistem yang digambarkan pada gambar 4 berikut.

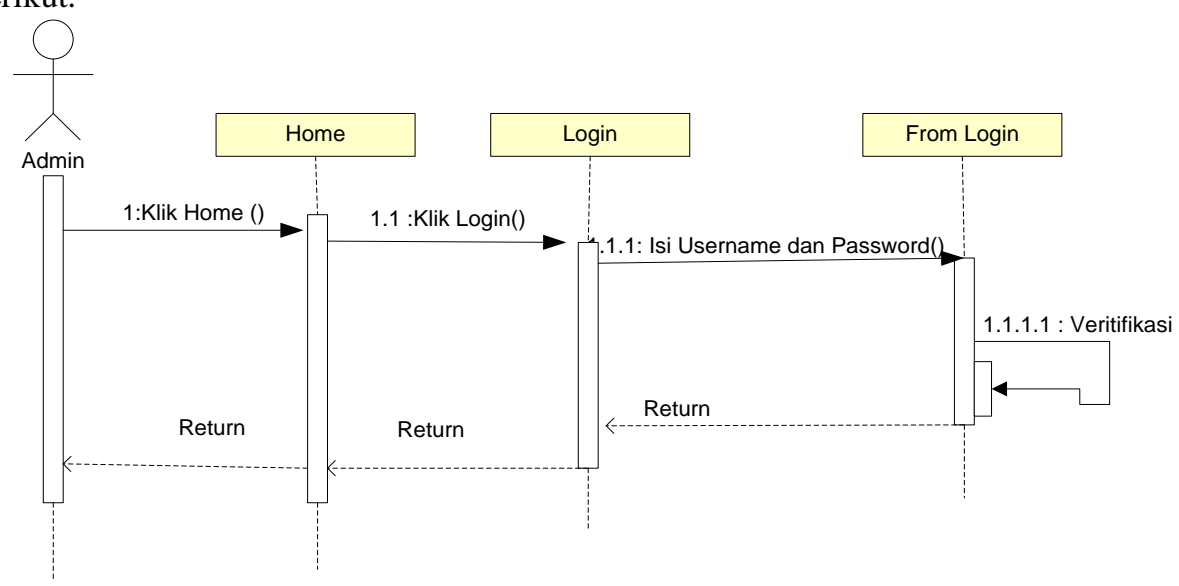

Gambar 4. Sequence Diagram Login Admin

\subsubsection{Class Diagram}

Class diagram memberikan gambaran hubungan antara tabel-tabel yang ada dalam database. Masing-masing class memiliki attribute dan metoda atau fungsi sesuai dengan proses yang terjadi, dapat dilihat pada gambar 5 berikut.

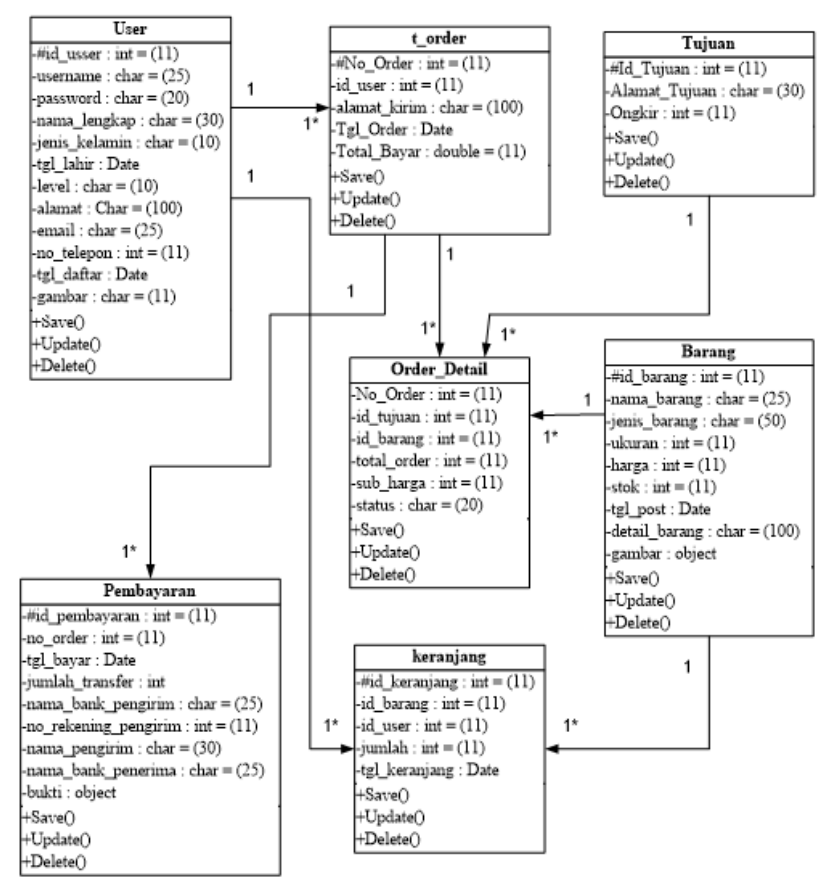

Gambar 5. Class Diagram 


\subsubsection{Struktur Program}

Desain struktur program merupakan suatu desain yang gambaran hubungan antara suatu modul program dengan modul program yang lain. Desain struktur dari yang diusulkan oleh penulis dapat dilihat pada gambar 6 . berikut.

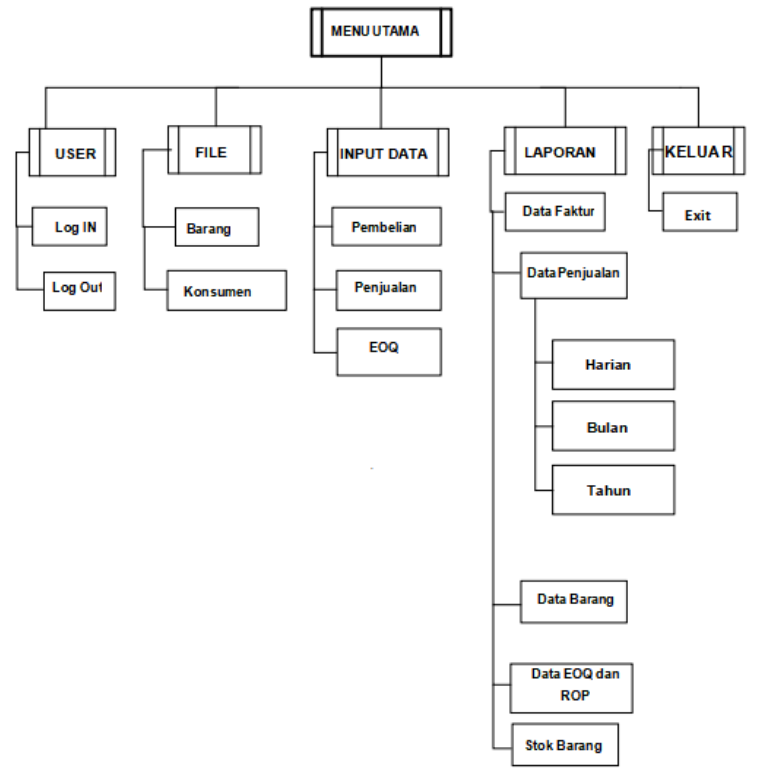

Gambar 6. Struktur Program Toko Ria Bangunan

\subsection{IMPLEMENTASI DAN PENGUJIAN SISTEM}

\subsubsection{Pengujian Sistem}

Pengujian sistem bertujuan untuk melihat apakah sistem yang dirancang sudah sesuai dengan apa yang diinginkan atau belum, setelah dilakukannya pengujian dan implementasi, kualitas sebuah system akan terlihat. Tampilan program yaitu merupakan sub bab yang menjelaskan tentang proses dimulainya sampai program ini selesai dieksekusi, point-point pada sub bab ini akan menjelaskan tentang bagaimana sebuah form dijalankan dan apa saja fungsi yang terdapat pada form tersebut.

\subsubsection{Tampilan Login}

Tampilan login merupakan tampilan awal pada saat aplikasi dijalankan. Pada tampilan menu login ini terdapat username dan password yang harus di isi untuk masuk ke dalam sistem. Tampilan halaman login dapat dilihat seperti pada Gambar 7:

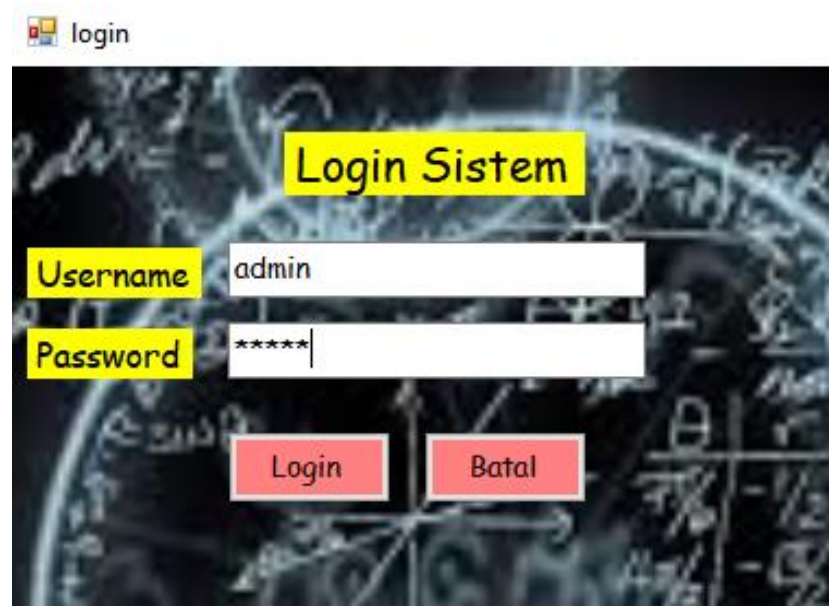

Gambar 7 Desain Login 


\subsubsection{Tampilan Menu Utama}

Tampilan menu utama merupakan halaman awal setelah melakukan login. Pada menu utama ini terdapat beberapa pilihan untuk kegiatan pada sistem seperti pada Gambar 8.

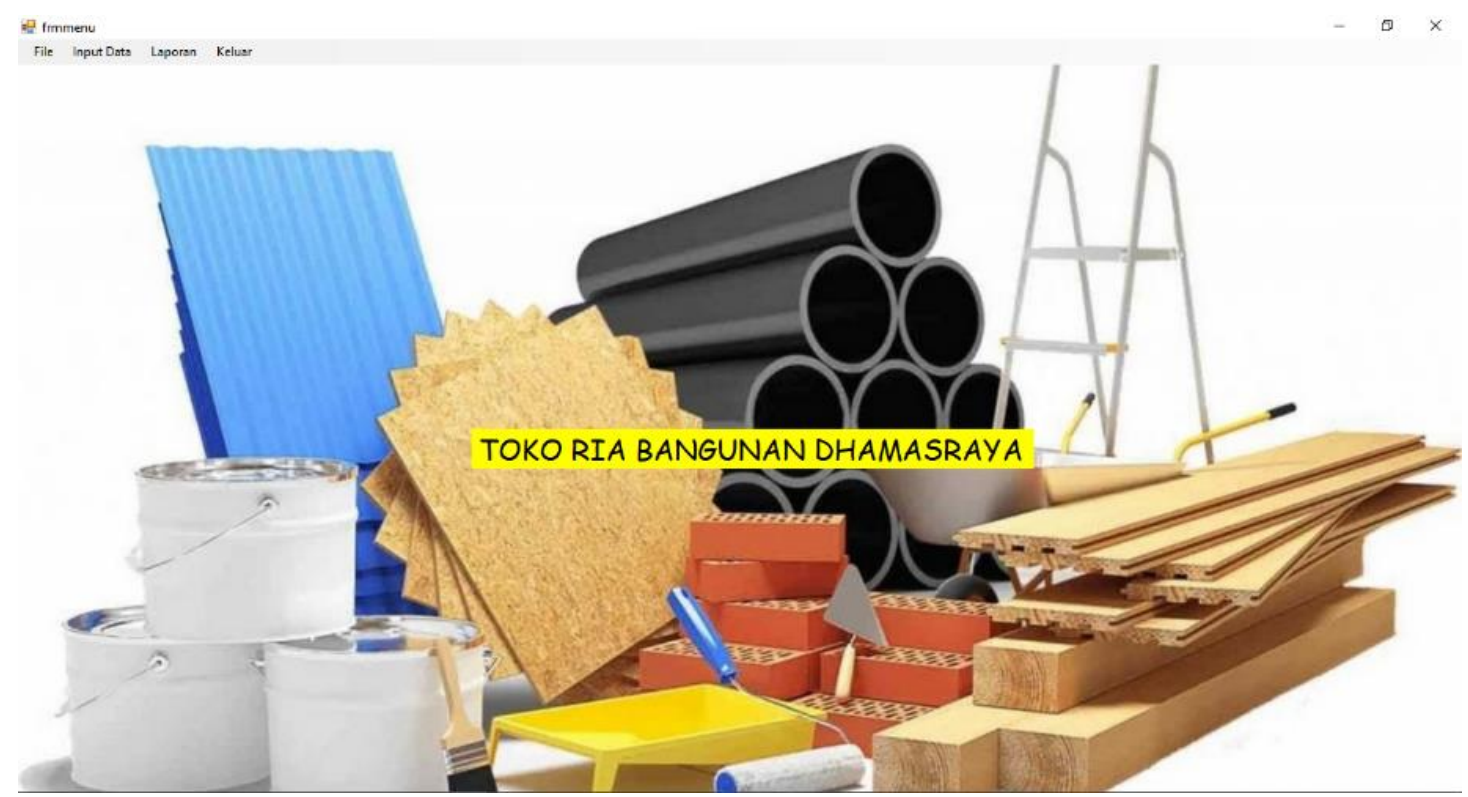

Gambar 8. Tampilan Menu Utama

\subsubsection{Tampilan Form Barang}

Tampilan form barang berisikan tentang kelola data barang seperti input, edit dan hapus data. Untuk masuk ke halaman form barang klik menu file barang pada menu dan akan muncul seperti pada Gambar 9.

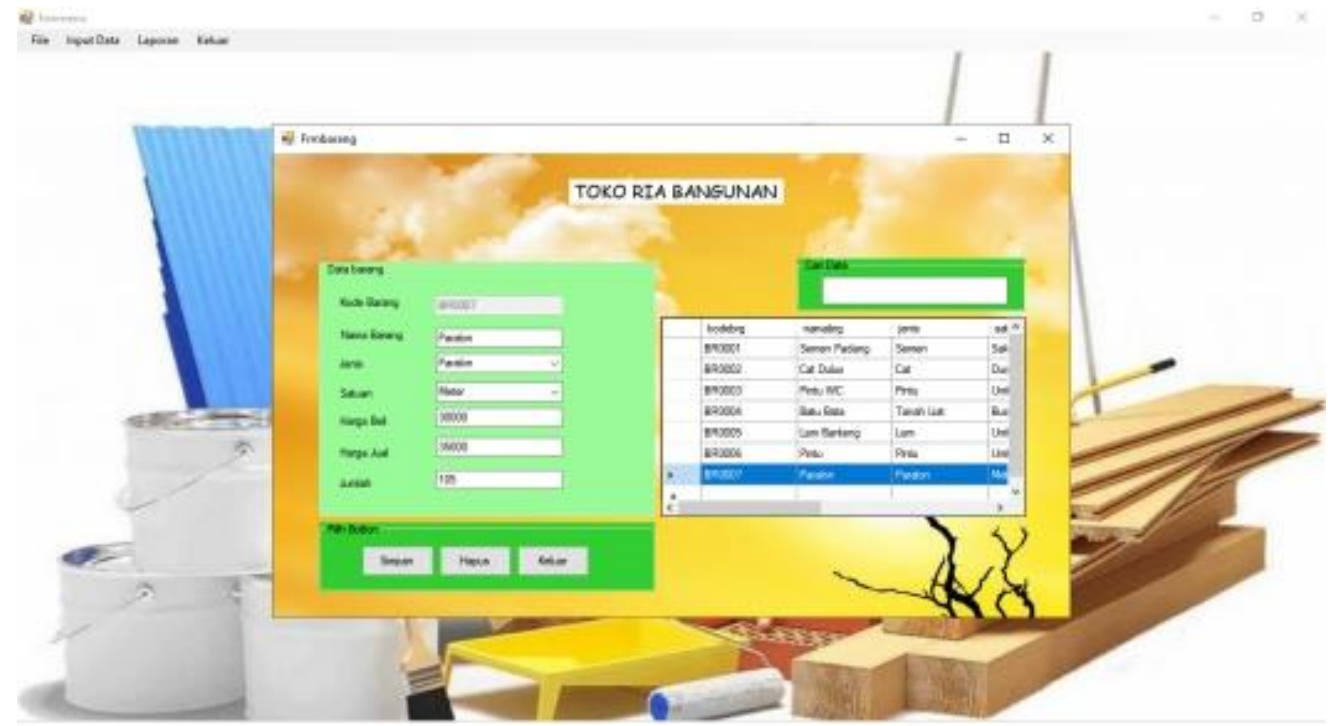

Gambar 9. Tampilan Form Barang

Perancangan Sistem Informasi Persediaan dan Penjualan Pada Toko Ria Bangunan Dengan Menggunakan Bahasa Pemrograman Visual Basic 2010 dan Database MYSQL( Novri Ultariani, Nursaka Putra, Amroni) 


\subsubsection{Tampilan Form Konsumen}

Tampilan form konsumen berisikan tentang kelola data konsumen seperti input, edit dan hapus data. Untuk masuk ke halaman form konsumen klik menu file konsumen pada menu dan akan muncul seperti pada Gambar 10.

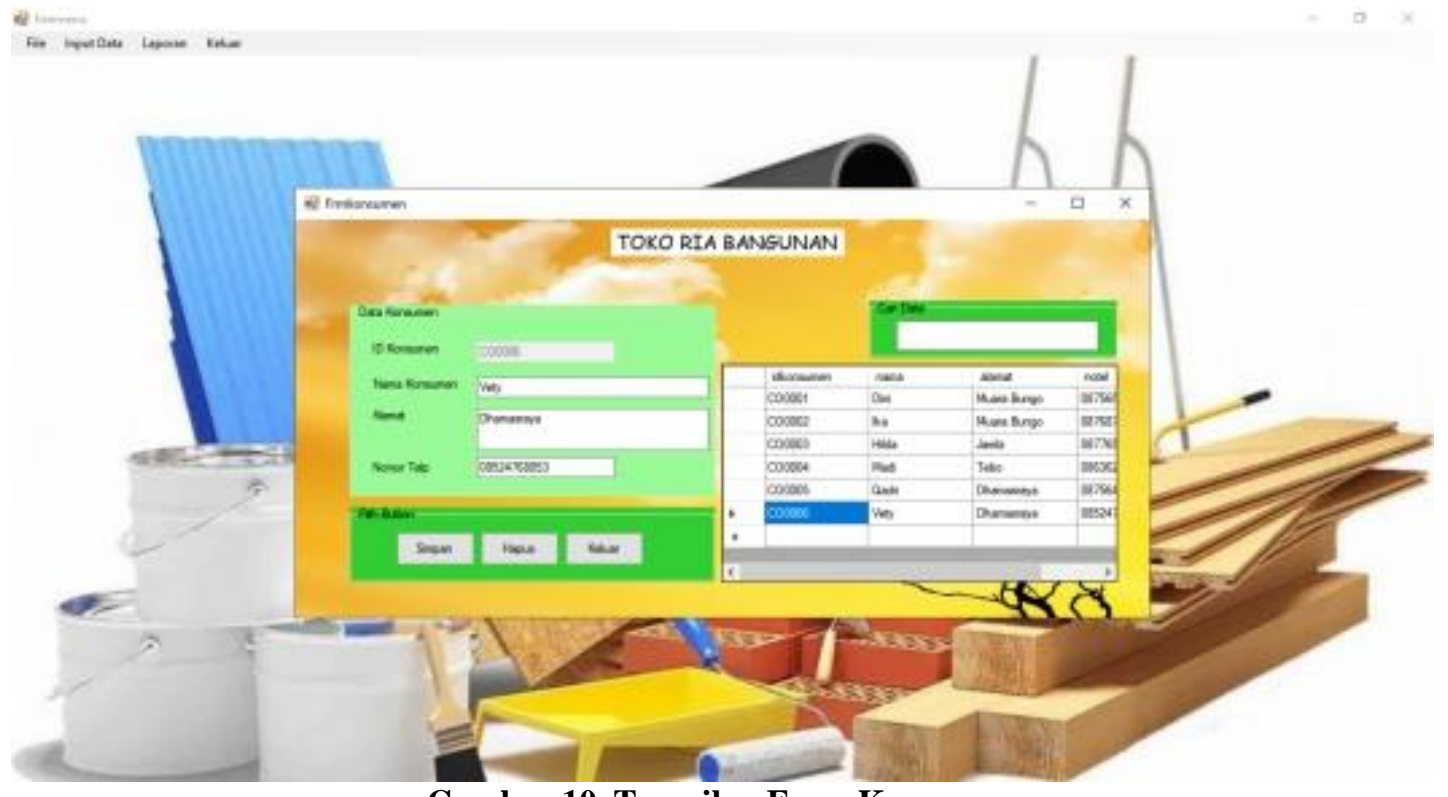

Gambar 10. Tampilan Form Konsumen

\subsubsection{Tampilan Form Pembelian}

Tampilan form pembelian berisikan tentang kelola data pembelian seperti input, edit dan hapus data. Untuk masuk ke halaman form pembelian klik menu file pembelian pada menu dan akan muncul seperti pada Gambar 11.

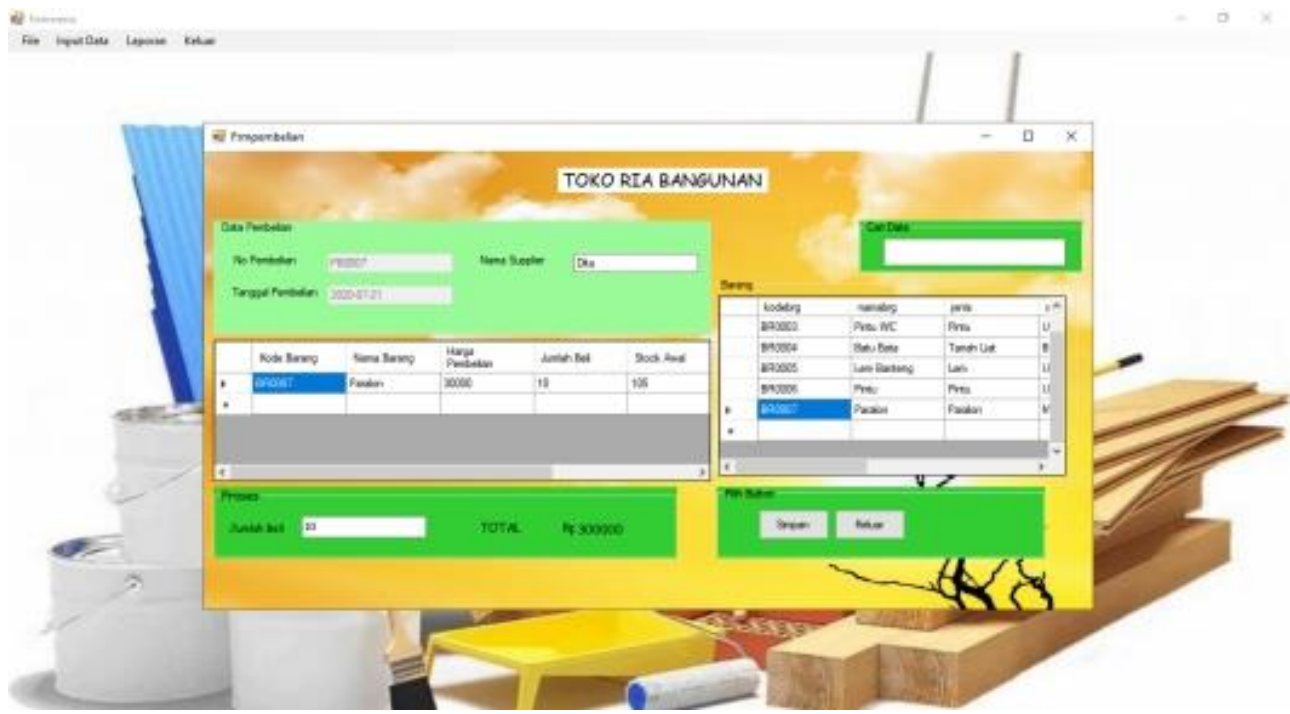

Gambar 11. Tampilan Form Pembelian

\subsubsection{Tampilan Form EOQ dan ROP}

Tampilan form penjualan berisikan tentang kelola data EOQ dan ROP barang seperti input, edit dan hapus data. Untuk masuk ke halaman form EOQ dan ROP klik menu file EOQ dan ROP pada menu dan akan tampil seperti pada Gambar 12. 


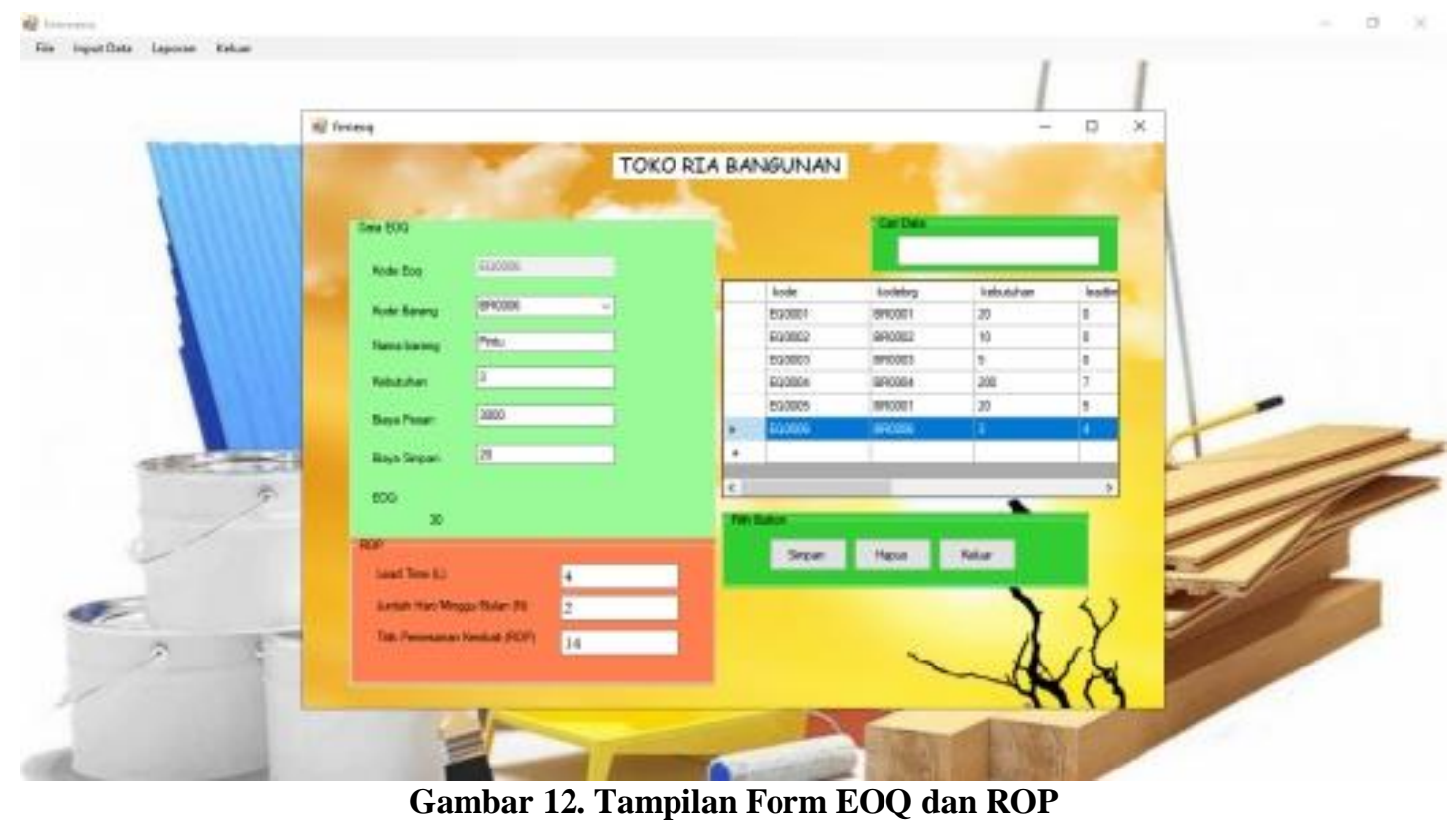

\subsubsection{Tampilan Laporan Data EOQ dan ROP}

Tampilan laporan data EOQ dan ROP berisikan tentang data EOQ dan ROP barang. Untuk menampilkan laporan data EOQ barang klik menu laporan data EOQ dan ROP pada menu dan akan tampil seperti pada Gambar 13.

\section{TOKO RIA BANGUNAN \\ LAPORAN DATA EOQ DAN ROP \\ Tanggal : $22 / 07 / 2020$}

\begin{tabular}{|l|c|r|r|r|r|r|r|r|}
\hline No & Kode Barang & Kebutuhan & Leadtime & Periode & Biaya Simpan & Biaya Pesan & Hasil & Interval \\
\hline 1 & BR0001 & 20 & 0 & 0 & 10 & 30 & 10 & 1 \\
2 & BR0002 & 10 & 0 & 0 & 20 & 30 & 5 & 1 \\
3 & BR0003 & 5 & 0 & 0 & 8 & 10 & 3 & 1 \\
4 & BR0004 & 200 & 7 & 20 & 4 & 5 & 22 & 1 \\
5 & BR0001 & 20 & 5 & 16 & 5 & 4 & 5 & 1 \\
6 & BR0006 & 3 & 4 & 2 & 20 & 3.000 & 30 & 1 \\
\hline
\end{tabular}

Dhamasraya, 22/07/2020

Ria

Gambar 13. Tampilan Laporan Data EOQ dan ROP

Perancangan Sistem Informasi Persediaan dan Penjualan Pada Toko Ria Bangunan Dengan Menggunakan Bahasa Pemrograman Visual Basic 2010 dan Database MYSQL( Novri Ultariani, Nursaka Putra, Amroni) 


\section{KESIMPULAN DAN SARAN}

Berdasarkan hasil pengembangan sistem yang telah penulis lakukan, penulis mencoba membuat suatu kesimpulan dan mengajukan beberapa saran-saran yang berhubungan dengan pembahasan yang telah dikemukakan di bab-bab sebelumnya.

\subsection{Kesimpulan}

Berdasarkan dari proses pembangunan aplikasi yang telah dilakukan oleh penulis, penulis menarik kesimpulan bahwa :

1. Dengan menggunakan aplikasi ini dapat membantu pihak toko dalam memberikan pelayanan yang terbaik kepada konsumen dan menunjang operasional pemasaran dalam dunia bisnis.

2. Dengan menggunakan aplikasi ini dapat membantu dalam melakukan persediaan stok barang dalam jumlah besar, sehingga mempermudah pihak Toko dalam melakukan pengelolaan.

\subsection{Saran-Saran}

Setelah menarik beberapa kesimpulan dari analisa yang dibuat, maka penulis mengajukan beberapa saran yang berkaitan dengan sistem yang baru dibangun ini. Saran-saran yang dapat diberikan sebagai berikut :

1. Untuk meningkatkan efisiensi kinerja bagian administrasi, disarankan menggunakan jasa komputer agar tidak ada kesalahan saat melakukan proses transaksi yang terjadi secara langsung.

2. Aplikasi ini dibangun menggunakan bahasa pemrograman Visual Basic 2010, pada perkembangan selanjutnya, diharapkan aplikasi ini dibangun dengan bahasa pemrograman yang lebih baru sesuai perkembangan zaman.

3. Melakukan pembaruan pada interface dan sistemnya karena seiring berjalannya waktu akan lahir lagi fitur baru yang lebih memanjakan pengguna.

4. Diharapkan program ini dapat bermanfaat bagi para pembaca.

\section{DAFTAR PUSTAKA}

[1] Asmara, Rini. 2014. Sistem Informasi Penjadwalan Kuliah (Studi Kasus : Institut Agama Islam Negeri (Iain) Imam Bonjol Padang). ISSN: 2338-2724.

[2] A.S, Rosa, Shalahuddin M. 2014. Rekayasa Perangkat Lunak. Bandung. Informatika.

[3] Enterprise Jubille. 2015. Pengenalan Pemrograman Komputer. Jakarta: Elex Media Kompotindo.

[4] Irwadi, Maulan. 2015. Penerapan Reorder Point Untuk Persediaan Bahan Baku Produksi Alat Pabrik Kelapa Sawit Pada PT. Swakarya Adhi Usaha Kabupaten Banyuasin. ISSN: 2407-2184.

[5] Kadir, Abdul. 2014. Sistem Informasi Edisi Revisi. Yogyakarta: Andi.

[6] Pratama I, Putu Agus Eka. 2014. Sistem Informasi Dan Implementasinya. Bandung: Informatika Bandung.

[7] Tohari, Hamim. 2014. ASTAH. Yogyakarta: ANDI. 